\title{
Missing Growth from Creative Destruction
}

\author{
By Philippe Aghion, Antonin Bergeaud, Timo Boppart, \\ Peter J. Klenow, And Huiyu Li*
}

\begin{abstract}
For exiting products, statistical agencies often impute inflation from surviving products. This understates growth if creatively-destroyed products improve more than surviving ones. If so, then the market share of surviving products should systematically shrink. Using entering and exiting establishments to proxy for creative destruction, we estimate missing growth in US Census data on non-farm businesses from 1983 to 2013. We find missing growth (i) equaled about one-half a percentage point per year; (ii) arose mostly from hotels and restaurants rather than manufacturing; and (iii) did not accelerate much after 2005, and therefore does not explain the sharp slowdown in growth since then. (JEL E23, E31, L14, L15, O30, O41)
\end{abstract}

Whereas it is straightforward to compute inflation for an unchanging set of goods and services, it is much harder to separate inflation from quality improvements and variety expansion amidst a changing set of items. In the US Consumer Price Index (CPI), over 3 percent of items exit the market each month (Bils and Klenow 2004). In the Producer Price Index (PPI) the figure is over 2 percent per month (Nakamura and Steinsson 2008).

The Boskin Commission (Boskin et al. 1996) highlighted the challenges of measuring quality improvements when incumbents upgrade their products. It also maintained that the CPI does not fully capture the benefits of brand new varieties. We argue that there exists a subtler, overlooked bias in the case of creative destruction. When the producer of the outgoing item does not produce the incoming item, the standard procedure at statistical offices is to resort to some form of imputation. Imputation inserts the average price growth among a set of surviving products that

\footnotetext{
*Aghion: Collège de France, 3 Rue d’Ulm, 75005 Paris, France, and London School of Economics (email: p.aghion@1se.ac.auk); Bergeaud: Banque de France, 31 Rue Croix des Petits Champs, 75001 Paris, France (email: antonin.bergeaud@banque-france.fr); Boppart: Institute for International Economic Studies, Stockholm University, SE-106 91 Stockholm, Sweden (email: timo.boppart@iies.su.se); Klenow: Department of Economics, Stanford University, Stanford, CA 94305 (email: klenow@stanford.edu); Li: Federal Reserve Bank of San Francisco, Economics Research, 101 Market Street, San Francisco, CA 94105 (email: tohuiyu@ gmail.com). Gita Gopinath was the coeditor for this article. We thank Raouf Boucekkine, Pablo Fajgelbaum, Kevin Fox, Bart Hobijn, Colin Hottman, and Stephen Redding for excellent discussions and Victoria De Quadros for superb research assistance. Ufuk Akcigit, Robert Feenstra, Xavier Jaravel, Chad Jones, Per Krusell, Torsten Persson, Ben Pugsley, John Van Reenen, four referees, and numerous seminar participants provided helpful comments. Any opinions and conclusions expressed herein are those of the authors and do not necessarily represent the views of the Federal Reserve System, the US Census Bureau, the Bank of France, or the Eurosystem. All results have been reviewed to ensure that no confidential information is disclosed. The authors have no relevant or material financial interests that relate to the research in this paper.

Go to https://doi.org/10.1257/aer.20171745 to visit the article page for additional materials and author disclosure statements.
} 